\title{
Analisis Daya Dukung Pondasi Bored Pile Tiang Tunggal Pada Proyek Rumah Sakit Internasional Surabaya
}

\author{
*Mikael Wora ${ }^{1}$ \\ ${ }^{1}$ Program Studi Teknik Sipil, Fakultas Teknik, Universitas Flores, Ende NTT \\ *) Correspondence e-mail : ata kelisoke@yahoo.co.id
}

\begin{abstract}
ABSTRAK
Paper ini menyajikan tentang hasil karya imliah skripsi penulis tentang studi banding perencanan pondasi tiang pancang beton dan bored pile, dimana konstruksi pondasi tiang pancang maupun bored pile adalah jenis pondasi dalam yang berfungsi untuk memikul beban yang disalurkan dari struktur atas bangunan bertingkat 3 bangunan gedung Rumah Sakit Internasional Surabaya.Tujuan studi untuk mengetahui jenis pondasi apa yang layak digunakanan sesuai kondisi tanah yang berada dibawah bangunan sebagai pijakan, agar bangunan tersebut tetap nyaman. Metode analisis yang digunakan antara lain : Metode Paulos dan Davis adalah rumus empris, Cone Penetrasi Tes (CPT) dan Standart Penetrasi Test (SPT) adalah data hasil penyelidikan dilapangan. Berdasarkan hasil analisis metode CPT memperoleh daya dukung sebesar 590,65 kN, metode SPT daya dukung sebesar 676,30 kN, Metode Paulos dan Davis untuk tiang tunggal daya dukung sebesar $831.00 \mathrm{kN}$. Hasil analisi menyimpulkan bahwa pondasi bored pile tiang tunggal layak digunakan karena dapat memikul beban layan yang diberikan sebesar $538.30 \mathrm{kN}$.
\end{abstract}

Kata Kunci: Daya dukung, Bored pile, CPT, SPT, Paulos dan Davis

\section{PENDAHULUAN}

Dalam bangunan gedung, pondasi merupakan salah satu komponen struktur yang paling penting, karena mempunyai fungsi untuk menahan kekokohan bangunan diatas tanah. Dalam perencanaan pondasi harus mempertibangkan penggunaan jenis pondasi, apabila salah memilih maka dapat mengakibatkan suatu bangunan akan menjadi retak, miring, sehingga bangunan tidak dapat berfungsi lagi dan membawa dampak kerugian yang besar.Pada proyek pembangunan gedung Rumah Sakit Internasional Surabaya dibangun diatas tanah lunak, yang berkohesinya lunak dan lapisannya cukup tebal. Kondisi tanah dasar ini memiliki daya dukung yang rendah, sehingga ketika menerima beban dari bangunan atas, dapat mengakibatkan penurunan yang sangat besar. Tujuan penelitian ini, untuk mengetahui apakah pondasi bored pile tiang tunggal aman dalam memikul beban struktur bangunan atas.

\section{Pondasi Tiang Pancang}

Pondasi tiang pancang adalah bagian dari struktur yang digunakan untuk menerima dan menyalurkan beban dari struktur atas ke tanah penunjang yang terletak pada kedalaman tertentu. Tiang pancang bentuknya panjang dan langsing yang menyalurkan beban ke tanah yang lebih dalam. Tiang pancang adalah bagian - bagian konstruksi yang dibuat dari kayu, beton, dan / atau baja, yang digunakan untuk meneruskan beban - beban permukaan ke tingkat - tingkat permukaan yang lebih rendah dalam massa tanah (Bowles, 1993).

Penggunaan pondasi tiang pancang sebagai pondasi bangunan apabila tanah yang berada dibawah dasar bangunan tidak mempunyai daya dukung (bearing capacity) yang cukup untuk memikul berat bangunan beban yang bekerja padanya (Sardjono HS, 1988). Atau apabila tanah yang mempunyai daya dukung yang cukup untuk memikul berat bangunan dan seluruh beban yang bekerja berada pada lapisan yang sangat dalam dari permukaan tanah kedalaman $>8 \mathrm{~m}$ (Bowles, 1991). Fungsi dan kegunaan dari pondasi tiang pancang adalah untuk memindahkan atau mentransfer beban-beban dari konstruksi di atasnya (super struktur) ke lapisan tanah keras yang letaknya sangat dalam.

Jenis-jenis tiang pancang digunakan:

Pondasi tiang pancang diklasifiksikan berdasarkan pemindahan beban dan mahan yang 
1. Berdasarkan Pemindahan beban yaitu tiang pancang tahanan ujung (end bearing pile) dan tiang pancang tahanan geser kulit (friction pile).

a. tiang pancang tahanan ujung (end bearing pile) adalah pondasi yang meneruskan beban melalui tahanan ujung tiang ke lapisan tanah yang paling keras. Hal ini terjadi apabila kondisi tanah dibawah ujung pondasi terdapat lapisan batuan keras.

b. tiang pancang tahanan geser kulit (friction pile) adalah pondasi yang meneruskan beban melalui tiang pancang kedalam tanah dengan enandalkan geseran kulit/ geseran selimut tiang pancang.

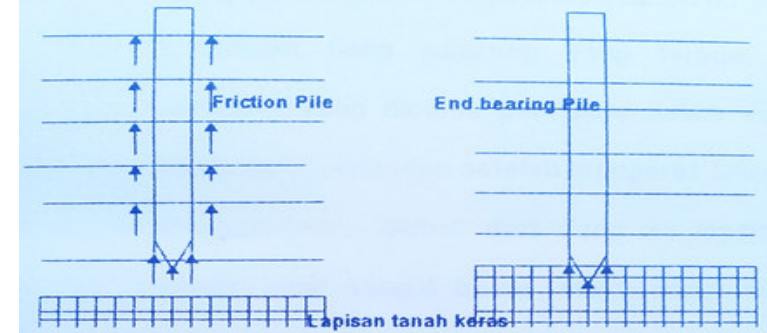

Gambar 1. Type pondasi friction pile dan end bearing pile (Sumber : Thomlinson 1977 hal. -11)

2. Menurut bahan yang digunakan : tiang pancang kayu, tiang pancang beton, tiang pancang baja, dan tiang pancang komposit.

\section{Penentuan Ukuran Tiang Pondasi}

Berdasarkan kondisi tanah dan kondisi pembebanan, maka dapat ditentukan ukuran dari tiang pancang beton yang dibutuhkan. Untuk mencegah ketentuan yang berlebihan pada saat pengankatan dan pemancangan, maka untuk tiang pancang bujur sangkar diberikan panjang aksimu yang diajukan seperti tertera pada table 1 .

\section{Tabel 1. Ukuran Tiang Pancang}

\begin{tabular}{cccc}
\hline \multicolumn{2}{c}{ Satuan Metrik } & \multicolumn{2}{c}{ Satuan Inggris } \\
Ukuran tiang (mm) & Panjang maks (m) & Ukuran tiang (inc) & Panjang maks (ft) \\
\hline 250 & 12 & 10 & 40 \\
300 & 15 & 12 & 50 \\
350 & 18 & 4 & 60 \\
400 & 2 & 16 & 70 \\
450 & 25 & 18 & 80 \\
\hline
\end{tabular}

Sumber : Thomlinson, $1971: 25$

Daya dukung tiang pancang tunggal berdasarkan kekuatan bahan

Menurut Sarjono (1991: 32)

Rumus :

Ptiang $=\sigma_{\text {bahan }} \times A_{\text {tiang }}$

Dimana :

$\mathrm{P}_{\text {tiang }}=$ Kekuatan yang diijinkan pada tiang pancang $(\mathrm{kg})$

$\sigma_{\text {bahan }}=$ Tegangan ijin bahan tiang $\left(\mathrm{kg} / \mathrm{cm}^{2}\right)$

$\mathrm{A}_{\text {tiang }}=$ Luas penampang tiang $\left(\mathrm{cm}^{2}\right)$

Daya dukung tiang Bores tunggal berdasarkan data sondir (CPT).

$Q a=\frac{p \cdot A}{3}+\frac{O \cdot f}{5}$

Dimana :

$\mathrm{Qa}=$ Daya dukung tanah ijin $(\mathrm{kg})$

$\mathrm{p}=$ Tekanan penetrasi konus

$\mathrm{f}=$ Jumlah hambatan pelekat $(\mathrm{kg} / \mathrm{cm})$ 
$\mathrm{A}=$ Luas penampang tiang $(\mathrm{cm} 2)$

$\mathrm{O}=$ keliling tiang $(\mathrm{cm})$

\section{Daya Dukung Tiang Bore Tunggal Berdasarkan Data Boring}

Daya dukung yang didasarkan pada data-data boring adalah menentukan kekuatan tanah dari hasil pemeriksaan dilapangan dengan alat sondir dengan ujung konus besudut $60^{\circ}$ dan luasan $10 \mathrm{~cm} 2$. Dua jenis alat sondir yang besarnya dipergunakan adalah standart point, yang hanya menunjukkan perlawanan penetrasi konus dan hambatan lekat. Daya dukung aksial pondasi dalam, uumnya terdiri dari dua bagian yaitu : daya dukung akibat gesekan dan daya dukung ujung (dasar) tiang. Dengan formulasinya sebagai berikut :

Qult $=$ Qsu + Qbu

Dimana :

Qult $=$ Daya dukung batas (ultimate) tiang

Qsu = Daya dukung batas gesekkan sepanjang badan tiang

$\mathrm{Qbu}=$ Daya dukung batas ujung tiang

Pada perhitungan daya dukung ujung, formulasnya dibedakan antara tanah lempung dan tanah pasir.

\section{Untuk tanah lempung}

Pada tanah lempung menggunakan persamaan sebagai beriku :

$\mathrm{Qbu}=$ Su.Nc.Ap

Dimana :

$\mathrm{Su}=$ kohesi atau kuat geser

$\mathrm{Nc}=$ Faktor daya dukung yang besarnya diambil 9

$\mathrm{Ap}=$ Luas penampang dasar (ujung) tiang

\section{Untuk tanah pasir}

Pada tanah pasir menggunakan persamaan sebagai berikut :

$\mathrm{Qbu}=\mathrm{q}^{\prime}(\mathrm{Nq}-1) \mathrm{Ap}$

Dimana :

q' = Efektif tanah pada ujung tiang

$\mathrm{Nq}=$ Faktor daya dukung yang merupakan fungsi sudut geser tanah $\Phi$ (gambar 2)

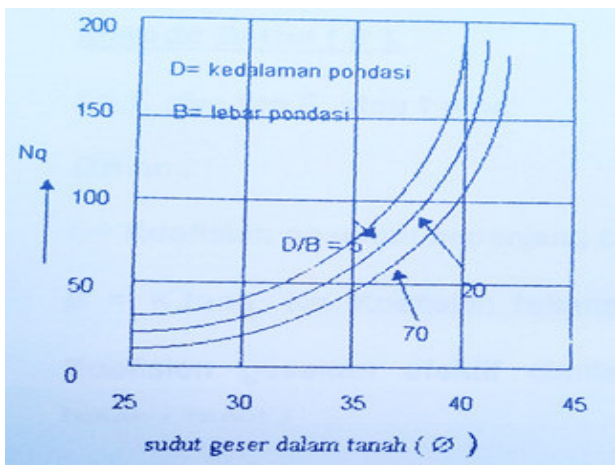

Gambar 2. Nilai Nq yang diturunkan oleh Berezantsev (Simon \& Menzies, 1970)

Sumber : Majalah Konstruksi, April 1997 : 4)

Perhitungan daya dukung geser, juga dibedakan atas tanah lempung dan tanah pasir. Secara umum persamaan adalah :

$\mathrm{Qsu}=\mathrm{f} . \mathrm{As}$

Dimana :

$\mathrm{f}=$ Koefisien gesekan sepanjang badan tiang

As $=$ Luas badan tiang 
Untuk tanah lempung, biasanya koefisien gesek (f), dihitung dengan metode alpha, metode lambda, metode betha. Sedangkan untuk tanah pasir, koefisien gesekkan (f) dihitung dengan persamaan :

Metode Betha $(\beta)$

$\mathrm{f}=\mathrm{K} \cdot \mathrm{q}$ 'va. $\tan \partial$ atau $\mathrm{f}=\beta \mathrm{q}$ '

Dimana :

$\mathrm{f}=$ Koefisien gesekkan sepanjang badan tiang

$\beta=\mathrm{K} \cdot \tan \partial$

$\mathrm{K}=$ Koefisien tekanan tanah lateral

$\tan \partial=$ Koefisien gesekan efektif diantara tiang pancang dan $\tan a h(\tan \Phi)$

\section{Metode Lambda (K)}

Menurut Vijayvergiya dan Focht (1972) menyajikan sebuah metode alternative untuk mendapatkan tahanan kulit (f) untuk sebuah tiang pancang dalam lempung sebagai berikut :

$\mathrm{f}=\Lambda\left(\mathrm{q}^{\prime}+2 \mathrm{Su}\right)$

Dimana :

$\mathrm{f}=$ Koefisien gesek sepanjang badan tiang

q' = Tegangan vertical efektif

$\mathrm{Su}=$ Kohesi atau kuat geser tak alit

$\Lambda=$ koefisien yang diperoleh dari (gambar 3 )

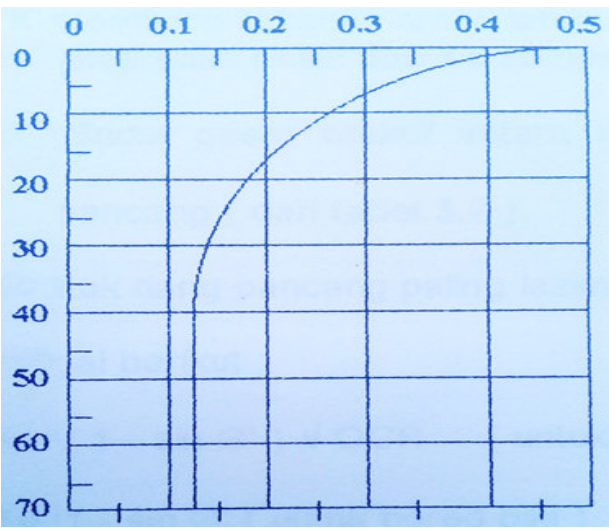

Gambar 3. Hubungan antara kedalaman penembusan dengan $\boldsymbol{K}$ (Vijayvergiya dan Focht 1972)

(Sumber : Bowles, $1984: 272$ )

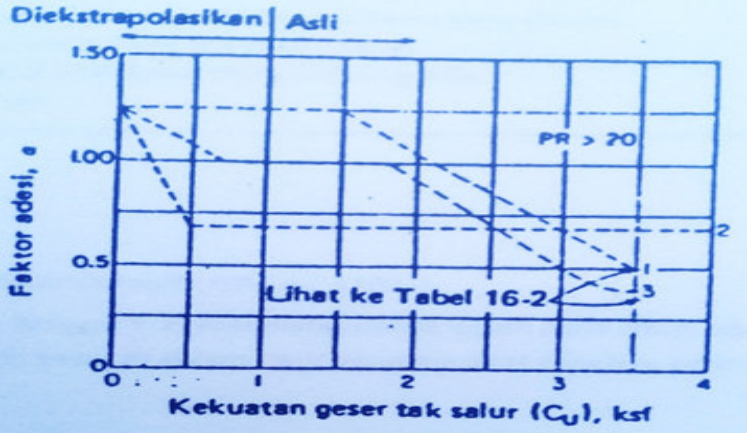

Gambar 4. Hubungan diantara tanah dan factor adhesi (Thomlinson, 1971)

(Sumber : Bowles, $1984: 270$ )

\section{Metode Alpha (a)}

Metode alpha diusulkan oleh Tomlinson (1971), pada dasarnya tahan kulit dihitung dengan formulasi sebagai berikut :

$\mathrm{f}=\alpha \mathrm{c}+\mathrm{q}^{\prime} \mathrm{K} \tan \Phi$

Dimana :

$\alpha=$ Koefisien dari gambar 3.4 atau table 3.6

$\mathrm{c}=$ kohesi rata-rata $(\mathrm{Su})$

q' = Tegangan vertical efektif

$\mathrm{K}=$ Koefisien tekanan tanah lateral Ko sampai kirakira 1,75

$\Phi=$ Sudut geser efektif antara tanah dan bahan tiang pancang (dari table 4)

Ko untuk tiang pancang lazi dihitung dengan rumus sebagai berikut :

Ko $=\left(1-\sin \Phi^{\prime}\right) \sqrt{ }$ OCR (untuk tiang pancang)

Ko $=1-\sin \Phi^{\prime}$ (untuk bored pile) 
Tabel 2. Nilai-nilai factor adhesi

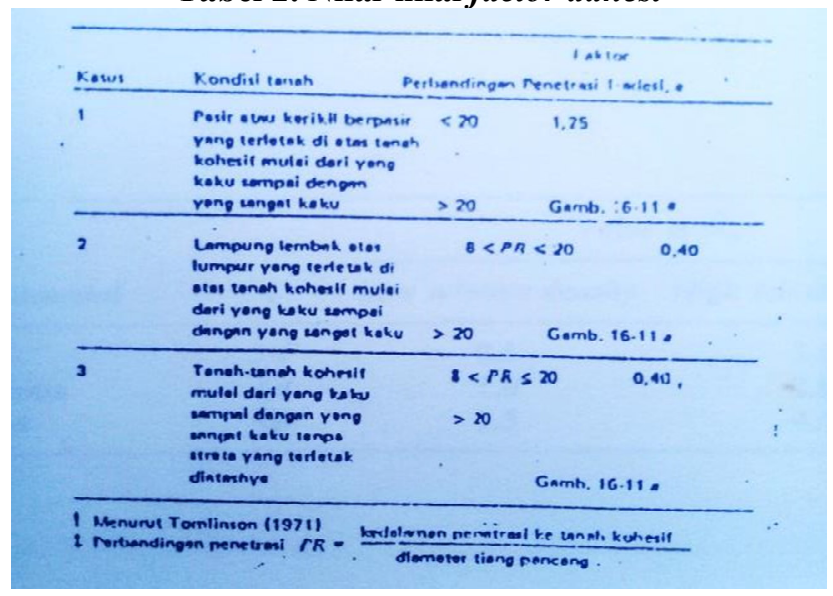

Sumber : Bowles, 1984 : 271)

Tabel 3. Sudutsudut gesekan $\partial$ antara beberapa bahan pondasi dengan tanah atau batuan

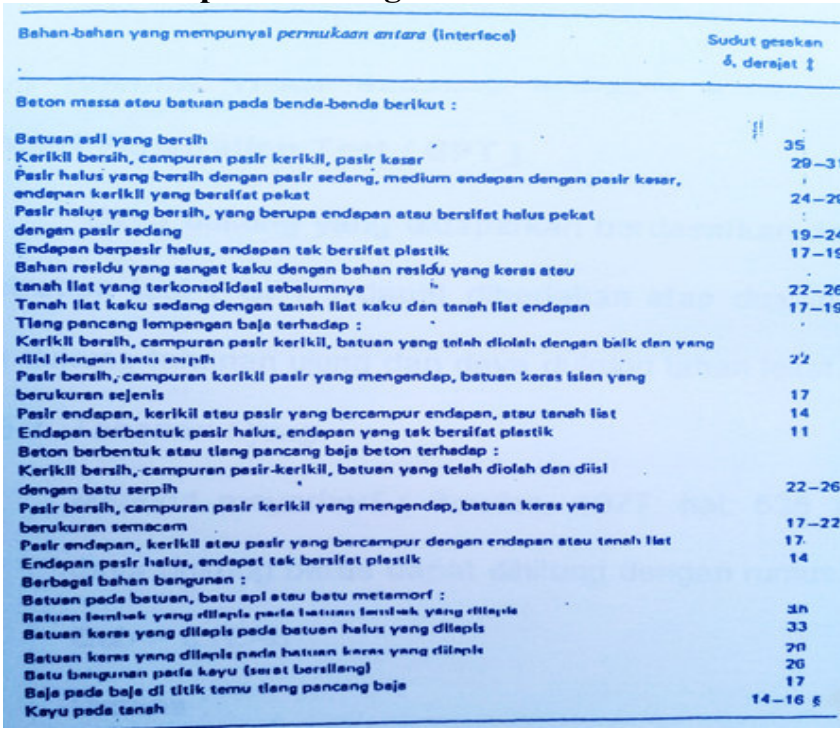

Sumber : Bowles, $1984: 30$ )
Tabel 4. Nilai K dan $\partial$

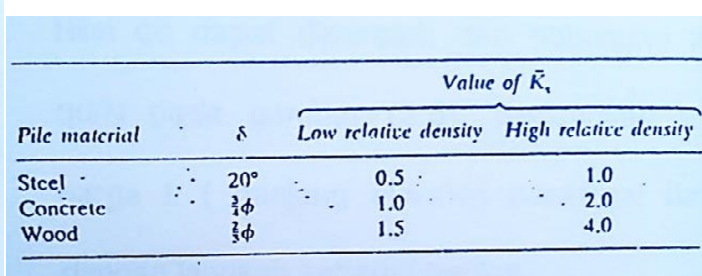

(Sumber : Tomlinson, 1977)

\section{Daya Dukung Tiang Pancang Tunggal Berdasarkan Data Standart Penetration Test (SPT)}

Daya dukung yang didapatkan berdasarkan data standart Penetration Test (SPT) dapat dibedakan atas dua macam yaitu daya dukung tahanan ujung dan daya dukung tahan lekat.

\section{Tahanan Ujung}

Menurut Menyerhorf (Bowles, 1977 : 535) besarnya daya dukung batas dapat dihitung dengan rumus berikut ini :

$\mathrm{Qub}=8 . \mathrm{N} \cdot \mathrm{Ab}$

Dimana :

$\mathrm{N}=$ Nilai SPT ujung tiang

$\mathrm{Ab}=$ Luas ujung tiang

Perkiraan daya dukung ujung tiang dapat diperoleh dari Suryono Sostrodarsono (1981: 100) sebagai berikut :

$\mathrm{Qub}=\mathrm{qd} . \mathrm{Ab}$ 
Nilai qd dapat diperoleh dari hubungan antara L/D dan $q d / N$ pada gambar 5. Sedangkan untuk mendapatkan harga L (panjang ekivalen penetrasi tiang) ditempuh dengan langkah sebagai berikut :

1. Menentukan harga $\mathrm{N}$ rencana dari tanah pondasi pada ujung tiang yang besarnya :

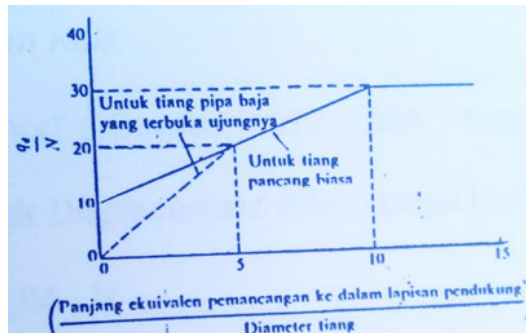

Gambar 5. Diagram hubungan antara $\mathbf{q d} / \mathbf{N}$ dan $\mathbf{L} / \mathbf{D}$

(Sumber : Suyono Sostrodarsono, 1981; 101)

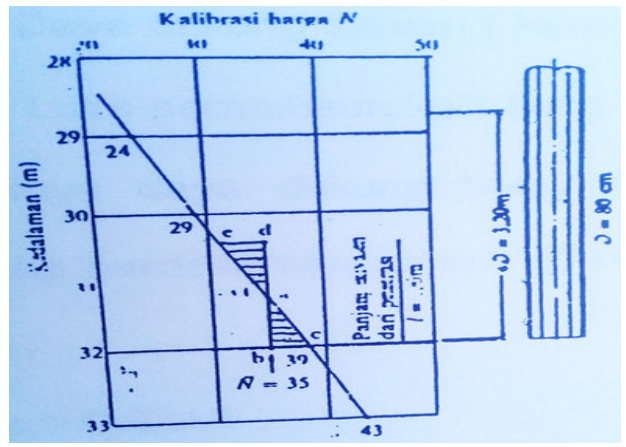

Gambar 6. kalibrasi harga $\mathbf{N}$

(Sumber : Suyono Sostrodarsono, 1981)

2. Harga $\mathrm{N}$ dapat diplot kegrafik hubungan SPT dan kedalaman, kemudian ditarik garis vertical melalui nilai $\mathrm{N}$ memotong kurva penetrasi. Setelah itu membuat garis horizontal melalu N1 sehingga terjadi sebuah segitiga ABC (lihat gambar 6.).

3. Kemudian ditentukan ditentukan titik $\mathrm{D}$ agar luasan segitiga $\mathrm{ABC}=\mathrm{ADE}$, panjang ekivalen dari penetrasi adalah BD.

\section{Tahanan Kulit}

Besar daya dukung tiang lekat dapat juga dihotung berdasarkan rumus dibawah ini (Suyono S. 1981 : 100)

Qus $=\mathrm{U} . \Sigma \mathrm{Li} . \mathrm{fi}$

Dimana :

Qus = Tahanan kulit batas (ton)

$\mathrm{U}=$ Panjang keliling tiang $(\mathrm{m})$

$\mathrm{Li}=$ Tebal lapisan tanah dengan memperhitungkan geseran dinding tiang $(\mathrm{m})$

$\mathrm{fi}=$ Besarnya gaya geser maksimum dari lapisan tanah dengan memperhitungkan geseran dinding tiang (ton/m2)

Besarnya fi tergantung pada jenis tanah pondasi dan jenis tiang.

Tabel 5. Intensitas gaya geser dinding tiang

\begin{tabular}{|c|c|c|}
\hline $\begin{array}{l}\text { Jenis } \\
\text { tanah pondasi }\end{array}$ & Tiang pracetak & $\begin{array}{l}\text { Tiang yang dicor } \\
\text { di tempat }\end{array}$ \\
\hline Tanah berpasir & $\frac{N}{5}(\leqq 10)$ & $\frac{N}{2}(\leqq 12)$ \\
\hline Tanah kohesif & $c$ atau $N(\leqq 12)$ & $\frac{c}{2} \operatorname{atau} \frac{N}{2}(\leqq 12)$ \\
\hline
\end{tabular}

Sumber : Suyono Sostrodarsono, 1981 : 102)

Nilai $\mathrm{N}$ pada table 5. diambil dari nilai rata-rata pada lapisan yang akan ditinjau.

Daya dukung ultimate :

Qult $=$ Qus + Qub

$\mathrm{Qa}=\mathrm{Qult} / \mathrm{n}$

Dimana :

Qult = Daya dukung batas $(\mathrm{kg})$

Qus = Daya dukung batas gesekan sepanjang tiang $(\mathrm{kg})$ 
$\mathrm{Qub}=$ Daya batas ujung tiang $(\mathrm{kg})$

$\mathrm{n}=$ Angka keamanan $(\mathrm{n}=2)$

\section{Daya dukung tiang menurut Poulos dan Davis}

Menurut H.G. Poulos dan E.H. Davis bahwa untuk mendapatkan daya dukung tiang dapat menggunakan rumus berdasarkan tiang pancang tunggal dan tiang pancang kelompok.

\section{Tiang pancang tunggal}

Daya dukung tiang pancang tunggal dapat diruuskan sebagai berikut :

$\mathrm{Pu}=\mathrm{Psu}+\mathrm{Pbu}-\mathrm{W}$

Dimana :

$\mathrm{Pu}=$ Daya dukung tiang pancang tunggal

Psu = Daya dukung habatan lekat

$\mathrm{Pbu}=$ Daya dukung ujung

$\mathrm{W}=$ Berat tiang pancang

$\mathrm{Psu}=\int \mathrm{C}(\mathrm{Ca}+\sigma \mathrm{v} \cdot \mathrm{Ks} \cdot \tan \Phi \mathrm{a}) \mathrm{dz}$

Dimana :

$\mathrm{C}=$ Keliling tiang

$\mathrm{L}=$ Panjang tiang pancang

$\mathrm{Pbu}=\mathrm{Ab}[\mathrm{C} . \mathrm{Nc}+\sigma \mathrm{vb} . \mathrm{Nq}+0.5 \gamma \mathrm{d} . \mathrm{N} \gamma]$

Dimana :

$\mathrm{Ab}=$ Luas dasar pondasi tiang pancang

$\mathrm{C}=$ Kohesi tanah

$\sigma v b=$ Gaya vertical dari tanah

$\mathrm{d}=$ Diameter tiang pancang

$\mathrm{Nc}, \mathrm{Nq}, \mathrm{N} \gamma=$ Faktor kapsitas daya dukung ujung, yang merupakan fungsi sudut geser dalam dari tanah, kompresi relative tanah dan geoetri tiang.

Menurut Poulos dan Davis dibedakan atas dua kondisi tanah yaitu :

Tiang Pancang Pada Lempung

Untuk tiang pancang pada lempung, dibedakan atas dua kondisi :

Undrained load capacity

Apabila tanah jenis (sautrated), maka $\Phi u=0, \Phi a=0, \Phi a=0, N q=1, N \gamma=0$, untuk $\Phi=0$ sehingga persamaan daya dukung menjadi :

$\mathrm{Pu}=\int \mathrm{C} \cdot \mathrm{Ca} \cdot \mathrm{dz}+\mathrm{Ab}(\mathrm{Cu} \cdot \mathrm{Nc}+\sigma \mathrm{vb})-\mathrm{W}$

Dimana :

$\mathrm{Cu}=$ Kohesi tanah pada dasar pondasi tiang

$\mathrm{Ca}=$ adhesi tiang tanah

Untuk tiang tanpa pelebaran dibawahnya maka persamaan diatas menjadi :

$\mathrm{Pu}=\int \mathrm{C} . \mathrm{Ca} \cdot \mathrm{dz}+\mathrm{Ab} \cdot \mathrm{Cu} \cdot \mathrm{Nc}$

Drainaned loads capacity

Pada kondisi ini adhesi tiang tanah $\mathrm{Ca}=0$, begitu pula factor kapasitas daya dukung ujung $\mathrm{Nc}$ dan $\mathrm{N} \gamma$ dapat diabaikan, sehingga persamaan menjadi :

$\mathrm{Pu}=\int \mathrm{C} . \sigma v^{\prime} \cdot \mathrm{Ks} \tan \Phi \mathrm{a}^{\prime} \cdot \mathrm{dz}+\mathrm{Ab} \cdot \sigma \mathrm{vb} \cdot \mathrm{Nq}-\mathrm{W}$

Dimana :

$\sigma v^{\prime}=$ Tekanan vertical efektif pada kedalaman z

$\sigma v b^{\prime}=$ Tekanan vertical efektif pada dasar tiang pancang

$\Phi a^{\prime}=$ Sudut geser dalam antara tiang dan tanah

\section{Tiang Pancang Pada Pasir}

Kondisi tiang pancang yang mempunyai ciri $\mathrm{Ca}=0$; C.Nc $=0$; dan $0.5 \gamma \mathrm{d} . \mathrm{N} \gamma$ sangat kecil, maka persamaan daya dukung tiang pancang :

$\mathrm{Pu}=\int$ Fw.C. $\sigma v^{\prime} . \mathrm{Ks} \tan \Phi^{\prime} \cdot \mathrm{dz}+\mathrm{Ab} . \sigma \mathrm{vb} \cdot \mathrm{Nq}-\mathrm{W}$

Dimana : 
$\sigma \mathrm{v}^{\prime}=$ Tekanan vertical efektif pada kedalaman z

$\sigma \mathrm{vb} b^{\prime}=$ Tekanan vertical efektif pada dasar tiang pancang

$\Phi^{\prime}=$ Sudut geser dalam antara tiang dan tanah $\left(\Phi^{\prime}=28+15 . D r\right)$

$\mathrm{Dr}=$ Kerapatan relative (Relative Density)

$\mathrm{FW}=$ Faktor koreksi

\section{HASIL DAN PEMBAHASAN}

Hasil analisi struktur bangunan dengan software SAP 90 beban yang dipikul pondasi:

Momen $\max =7.64 \mathrm{kN} . \mathrm{m} ; \mathrm{Vmax}=538.3 \mathrm{kN} ; \mathrm{Hmax}=179.6 \mathrm{kN}$ yang harus dipikul oleh 1 tiang bored pile berdiameter $50 \mathrm{~cm}$. Mutu material yang digunakan : Beton ( $\left.\mathrm{f}^{\prime} \mathrm{c}=40 \mathrm{Mpa}\right)$, Besi beton $(\mathrm{U}=24 \mathrm{Mpa})$.

\section{Kekuatan daya dukung pondasi tiang tunggal berdasarkan :}

\section{Kekuatan bahan;}

Ptiang $=$ Atiang . $\sigma$ 'bahan

$$
\begin{aligned}
& =0.25 \times 3.14 \times 0.5 \times 0.5 \times 2,24 \\
& =760,48 \mathrm{kN}
\end{aligned}
$$

Dava Dukung Berdasarkan Data Sondir (CPT);

\begin{tabular}{|c|c|c|c|c|c|}
\hline $\begin{array}{c}\text { Kedalaman } \\
\text { (meter) }\end{array}$ & $S(\mathrm{~kg} / \mathrm{cm})$ & $\mathrm{S}(\mathrm{kN} / \mathrm{cm})$ & $\begin{array}{c}\text { Kedalaman } \\
\text { (meter) }\end{array}$ & $\mathrm{S}(\mathrm{kg} / \mathrm{cm})$ & $\mathrm{S}(\mathrm{kN} / \mathrm{cm})$ \\
\hline $1.00-9.00$ & 2.5 & 0.025 & 15.40 & 80 & 0.80 \\
\hline 10.00 & 8 & 0.08 & 15.60 & 70 & 0.70 \\
\hline 11.00 & 5 & 0.05 & 15.80 & 65 & 0.65 \\
\hline 12.00 & 10 & 0.10 & 16.00 & 60 & 0.60 \\
\hline 13.00 & 25 & 0.25 & 16.20 & 68 & 0.68 \\
\hline 13.60 & 35 & 0.35 & 16.40 & 65 & 0.65 \\
\hline 13.80 & 20 & 0.20 & 16.60 & 70 & 0.70 \\
\hline 14.00 & 50 & 0.50 & 16.80 & 80 & 0.80 \\
\hline 14.20 & 45 & 0.45 & 17.00 & 85 & 0.85 \\
\hline 14.40 & 70 & 0.70 & 17.20 & 87 & 0.87 \\
\hline 14.60 & 60 & 0.60 & 17.40 & 90 & 0.90 \\
\hline 14.80 & 90 & 0.90 & 17.60 & 110 & 1.10 \\
\hline 15.00 & 100 & 1.00 & 17.80 & 145 & 1.45 \\
\hline 15.20 & 90 & 0.90 & 18.00 & 150 & 1.50 \\
\hline
\end{tabular}

Tabel 6. Data Sondir (CPT)

$\mathrm{Cn} 2=8 \mathrm{~S}$ di atas alas pondasi $=4.00 \mathrm{~m}$, maka berdasarkan table dimulai dari $12.00 \mathrm{~m} \mathrm{~s} / \mathrm{d} 16.00 \mathrm{~m}$.

$C n 2=\frac{S 12.00+S 12.20+S 12.40+\cdots+S 16.00+n . S 16.00}{n \times 2}$

$C n 2=\frac{0.10+0.10+0.10+\cdots+0.60+21 \times 0.60}{21 \times 2}$

$\mathrm{Cn} 2=0.64 \mathrm{kN}$

$\mathrm{Cn} 1=4 \mathrm{~S}$ di bawah alas pondasi $=2.00 \mathrm{~m}$, maka berdasarkan table dimulai dari $16.00 \mathrm{~m} \mathrm{~s} / \mathrm{d} 18.00 \mathrm{~m}$.

$C n 2=\frac{S 16.00+S 16.20+S 16.40+\cdots+S 18.00}{n}$

$C n 2=\frac{0.60+0.68+0.65+\cdots+1.50}{7}$

$\mathrm{Cn} 2=0.92 \mathrm{kN}$

$C R=\frac{C n 1+C n 2}{2}$

$C R=\frac{0.64+0.92}{2}=0.78 \mathrm{kN}$ 
Tabel 7. Gaya geser dinding tiang

\begin{tabular}{|c|c|c|c|c|c|}
\hline $\begin{array}{c}\text { Kedalaman } \\
\text { (meter) }\end{array}$ & $\mathrm{S}(\mathrm{kg} / \mathrm{cm})$ & $\mathrm{S}(\mathrm{kN} / \mathrm{cm})$ & $\begin{array}{c}\text { Kedalaman } \\
\text { (meter) }\end{array}$ & $\mathrm{S}(\mathrm{kg} / \mathrm{cm})$ & $\mathrm{S}(\mathrm{kN} / \mathrm{cm})$ \\
\hline $1.00-5.00$ & 25 & 0.25 & 11.00 & 100 & 1.00 \\
\hline 6.00 & 50 & 0.50 & 12.00 & 125 & 1.25 \\
\hline 7.00 & 50 & 0.50 & 13.00 & 180 & 1.80 \\
\hline 8.00 & 70 & 0.70 & 14.00 & 240 & 2.40 \\
\hline 9.00 & 70 & 0.70 & 15.00 & 300 & 3.00 \\
\hline 10.00 & 100 & 1.00 & 16.00 & 500 & 5.00 \\
\hline
\end{tabular}

$\mathrm{Qa} \quad=\mathrm{p} . \mathrm{A} / 3+\mathrm{f} . \mathrm{O} / 5$

$=0.78 \times 2000 / 3+0.45 \times 5 \times 157 / 5$

$=590,65 \mathrm{kN}$

Dava Dukung berdasarkan Data Boring;

Tabel 8. Data Boring

\begin{tabular}{|c|c|}
\hline $\begin{array}{l}0.00 \mathrm{~m} \\
0.50 \mathrm{~m}\end{array}$ & $\begin{array}{l}\text { SM (pasir) ysat }=1970 \mathrm{~kg} / \mathrm{cm}^{\prime} \\
\Phi=21^{\circ}\end{array}$ \\
\hline $\begin{array}{l}0.50 \mathrm{~m} \\
-\overline{0} \mathrm{~m}\end{array}$ & $\begin{array}{l}C L \text { (lempung) } \gamma s a t=1704 \mathrm{~kg} / \mathrm{cm}^{2} \\
C u=0.21 \mathrm{~kg} / \mathrm{cm}^{2} \\
\Phi=0^{\circ}\end{array}$ \\
\hline $\begin{array}{l}3.00 \mathrm{~m} \\
12.50 \mathrm{~m}\end{array}$ & $\begin{array}{l}C L \text { (lempung) Ysat }=1762 \mathrm{~kg} / \mathrm{cm}^{2} \\
C u=0.81 \mathrm{~kg} / \mathrm{cm}^{2} \\
=0^{\circ}\end{array}$ \\
\hline $\begin{array}{l}12.50 \mathrm{~m} \\
- \\
13,00 \mathrm{~m}\end{array}$ & $\begin{array}{l}S M \text { (pasir) ysat }=1972 \mathrm{~kg} / \mathrm{cm}^{2} \\
\Phi=26^{\circ}\end{array}$ \\
\hline $\begin{array}{l}13.00 \mathrm{~m} \\
15.60 \mathrm{~m}\end{array}$ & $\begin{array}{l}C L \text { (lempung) Ysat }=1758 \mathrm{~kg} / \mathrm{cm}^{2} \\
C u=0.23 \mathrm{~kg} / \mathrm{cm}^{2} \\
t=0^{\circ}\end{array}$ \\
\hline $\begin{array}{l}15.60 \mathrm{~m} \\
16.00 \mathrm{~m}\end{array}$ & $\begin{array}{l}C L \text { (lempung) } \gamma s a t=1814 \mathrm{~kg} / \mathrm{cm}^{2} \\
C u=0.20 \mathrm{~kg} / \mathrm{cm}^{2} \\
\Phi=0^{\circ}\end{array}$ \\
\hline
\end{tabular}

Untuk End Bearing Pile

Untuk $\Phi=35^{\circ}, \mathrm{D} / \mathrm{B}=50$. Maka Nq $=50$ (lihat gambar 2)

Untuk $\Phi=30^{\circ}, \mathrm{D} / \mathrm{B}=50$. Maka Nq $=7$ (lihat gambar 2)

$\mathrm{Ko} 1=(1-\sin \Phi)$

$\mathrm{Ko1}=\left(1-\sin 35^{\circ}\right)$

$\mathrm{Ko1}=0.43$

$\mathrm{Ko} 2=(1-\sin \Phi)$

$\mathrm{Ko} 2=\left(1-\sin 30^{\circ}\right)$

$\mathrm{Ko} 2=0.50$

Qbu1 = q' $(\mathrm{Nq}-1)$ Ap (untuk lapisan 1 dan 4 tanah pasir)

Qbu1 $=17.36 \times 0.5(50-1) 0.2$

$\mathrm{Qbu}=85.064 \mathrm{kN}$

Qbu2 $=$ Su.Nc.Ap (untuk lapisan 2,3,5 dan 6 tanah lempung)

$\mathrm{Qbu} 2=21 \times 9 \times 0.2$

Qbu2 $=37.80 \mathrm{kN}$

Hasil analisis selanjutnya lihat pada table di bawah ini

Tabel 9. Rekapitulasi Friction Pile

\begin{tabular}{ccccccc}
\hline No. & Nc & $\mathbf{q}^{\prime}$ & Nq & Ap & Su & Qbu (kN) \\
\hline 1 & - & $17.36 \times 0.5$ & 50 & 0.2 & - & 85.064 \\
2 & 9 & - & - & 0.2 & 21 & 37.80 \\
3 & 9 & - & - & 0.2 & 18 & 32.40 \\
4 & - & $17.36 \times 0.5$ & 7 & 0.2 & - & 1442.20 \\
5 & 9 & - & - & 0.2 & 23 & 41.40 \\
6 & 9 & - & - & 0.2 & 20 & 36.00 \\
\hline \multicolumn{7}{r}{} \\
\hline
\end{tabular}


Untuk Friction Pile

$\mathrm{f} 1=\mathrm{q}^{\prime} \cdot \mathrm{K} \tan \partial$

$\mathrm{f} 1=17.36 \times 0.5 \times 0.43 \tan 26^{0}$.

$\mathrm{fl}=1.82 \mathrm{kN} / \mathrm{m}^{2}$.

$\mathrm{Qsu} 1=\mathrm{f} 1 . \mathrm{As}$

Qsu1 $=3.34 \times 3,14 \times 0.5 \times 0.5$

Qsu1 $=1.43 \mathrm{kN}$

$\mathrm{f} 2=\kappa\left(\mathrm{q}^{\prime}+2 \mathrm{Su}\right)$

$\mathrm{f} 2=0.38(17.04 \times 3+2 \times 21)$

$\mathrm{f} 2=35.38 \mathrm{kN} / \mathrm{m}^{2}$.

Qsu2 $=\mathrm{f} 2$.As

Qsu1 $=35.38 \times 3,4 \times 0.5 \times 2.5$

Qsu1 $=138.87 \mathrm{kN}$

Hasil selanjutnya lihat pada table dibawah ini

Tabel 10. Rekapitulasi Qsu

\begin{tabular}{llllllll}
\hline No. & $\boldsymbol{\Lambda}$ & $\mathbf{q}$ & $\mathbf{K} \tan \boldsymbol{\partial}$ & $\mathbf{S u}$ & $\mathbf{A S}$ & $\mathbf{f}\left(\mathbf{k N} / \mathbf{~ m}^{\mathbf{2}}\right)$ & $\mathbf{Q s u}(\mathbf{k N})$ \\
\hline 1 & - & 8.68 & 0.385 & - & $0.5 \times 1.57$ & 1.82 & 1.43 \\
2 & 0.38 & 51.12 & - & 21 & $2.5 \times 1.57$ & 35.38 & 138.87 \\
3 & 0.22 & 220.25 & - & 18 & $9.5 \times 1.57$ & 56.375 & 842.833 \\
4 & - & 256.36 & 0.372 & - & $0.5 \times 1.57$ & 83.76 & 65.752 \\
5 & 0.18 & 274.25 & - & 23 & $2.6 \times 1.57$ & 57.65 & 235.330 \\
6 & 0.17 & 290.24 & - & 20 & $0.4 \times 1.57$ & 56.4 & 35.256 \\
\hline \multicolumn{7}{c}{ Jumlah } \\
\hline
\end{tabular}

Qult $=$ Qbu + Qsu

Qult $=36+1317.471$

Qult $=1353.471 \mathrm{kN}$

Qijin $=$ Qult $/ 2$

Qijin $=1353.471 / 2=676.74 \mathrm{kN}>543 \mathrm{kN}(\mathrm{OK})$

\section{Dava Dukung Berdasarkan Data SPT;}

1. Mencari panjang ekivalen dari penetrasi tiang.

a. Harga $\mathrm{N}$ pada ujung tiang, $\mathrm{N} 1=22$

b. Nrata-rata pada jarak 4D dari ujung bawah tiang keatas, $\mathrm{N} 2=(26+27+22+30) / 4=26.25$

2. Daya dukung pada ujung karena tiang pancang dari beton yang ujungnya tertutup, maka dipakai garis tebal pada gambar 3.5.

$\mathrm{L} / \mathrm{D}=.2 / 0,5=4$, maka diperoleh $\mathrm{qd} / \mathrm{N}=18$

$\mathrm{Qd}=18 \mathrm{~N} 2=18 \times 26.25=472.50 \mathrm{ton} / \mathrm{m}=4725 \mathrm{kN} / \mathrm{m}$

Qd.A $=4725 \times 0.25 \times 3.14 \times 0.5 \times 0.5=945 \mathrm{kN}$

3. Gaya gesek aksimumm dinding tiang

\section{Tabel 11. Data Boring log}

\begin{tabular}{cc}
\hline Kedalaman (meter) & Jumlah Pukulan (N) \\
\hline $0.50-10.25$ & 1 \\
12.25 & 5 \\
13.75 & 16 \\
15.25 & 27 \\
16.75 & 24 \\
\hline
\end{tabular}

Pada kedalaman : (data boring log)
a. $\quad 16.00$ meter, $\mathrm{N}=22$
b. $\quad 15.25$ meter, $\mathrm{N}=27$
c. 14.88 meter, $\mathrm{N}=26$ 
d. $\quad 14.00$ meter, $\mathrm{N}=30$

Tabel. 12. Analisis Friction Pile

\begin{tabular}{lllllll}
\hline Kedalaman (m) & $\begin{array}{c}\text { Ketebalan Li } \\
(\mathbf{m})\end{array}$ & Lapisan & $\mathbf{N}$ & $\begin{array}{c}\mathbf{f i} \\
(\mathbf{t} / \mathbf{m} \mathbf{2})\end{array}$ & $\begin{array}{c}\text { fi.li } \\
(\mathbf{t} / \mathbf{m})\end{array}$ & $\begin{array}{c}\text { fi.li } \\
(\mathbf{k N} / \mathbf{m})\end{array}$ \\
\hline $0.0-0.50$ & 0.5 & Pasir & 1 & 1 & 0.5 & 5 \\
$0.50-3.00$ & 2.5 & Lempung & 1 & 1 & 2.5 & 25 \\
$3.00-12.50$ & 9.5 & Lempung & 3.5 & 3.5 & 33.25 & 332.5 \\
$12.50-13.00$ & 0.5 & Pasir & 10 & 2 & 1 & 10 \\
$13.00-15.60$ & 2.6 & Lempung & 19.75 & 3.95 & 10.27 & 102.7 \\
$15.60-16.00$ & 0.4 & Lempung & 23 & 4.6 & 1.84 & 560.3 \\
\hline \multicolumn{1}{c}{} & $\mathbf{1 6}$ & & & & $\mathbf{4 8 . 3 6}$ & $\mathbf{9 6 0 . 3}$ \\
\hline
\end{tabular}

4. Daya dukung geser

$\mathrm{U} \Sigma \mathrm{Li} . \mathrm{fi}=0,48 \times 690,3=1083,8 \mathrm{kN}$

5. Daya dukun ultimit

$$
\begin{aligned}
& \text { Qult }=\text { qd.A }+ \text { U. } . \text { Li.fi }=945+1083.8=384,901 \mathrm{kN} \\
& \begin{aligned}
\text { Qijin }=\text { Qult } / 3 \\
\text { Qijin }=2028.8 / 3 \\
\quad=676.30 \mathrm{kN}
\end{aligned}
\end{aligned}
$$

\begin{tabular}{|c|c|}
\hline $\begin{array}{l}0.00 \mathrm{~mm} \\
0.50 \mathrm{~mm}\end{array}$ & $\begin{array}{l}\text { SMA (pasir) Ysat }=1970 \mathrm{~kg} / \mathrm{cm}^{2} \\
\mathbf{q}=21^{\circ}\end{array}$ \\
\hline $\begin{array}{l}0.50 \mathrm{~m} \\
3.00 \mathrm{~mm}\end{array}$ & $\begin{array}{l}C L \text { (lempung) } Y s a t=1704 \mathrm{~kg} / \mathrm{cm}^{2} \\
C u=0.21 \mathrm{~kg} / \mathrm{cm}^{2} \\
=0^{\circ}\end{array}$ \\
\hline $\begin{array}{l}3.00 \mathrm{~m} \\
12.50 \mathrm{~m}\end{array}$ & $\begin{array}{l}C L\left(\text { lempung) } \mathrm{Ysat}=1762 \mathrm{~kg} / \mathrm{cm}^{2}\right. \\
C u=0.81 \mathrm{~kg} / \mathrm{cm}^{2} \\
Y=0^{\circ}\end{array}$ \\
\hline $\begin{array}{l}12.50 \mathrm{~m} \\
13,00 \mathrm{~m}\end{array}$ & $\begin{array}{l}\text { SMI (pasir) ysat }=1972 \mathrm{~kg} / \mathrm{cm}^{2} \\
\mathbf{I}=26^{\circ}\end{array}$ \\
\hline $\begin{array}{l}13.00 \mathrm{~m} \\
15.60 \mathrm{~mm}\end{array}$ & $\begin{array}{l}C L(\text { lempung }) ~ Y s a t=1758 \mathrm{~kg} / \mathrm{cm}^{2} \\
C u=0.23 \mathrm{~kg} / \mathrm{cm}^{2} \\
\Phi=0^{\circ}\end{array}$ \\
\hline $\begin{array}{l}15.60 \mathrm{~m} \\
16.00 \mathrm{~m}\end{array}$ & $\begin{array}{l}C L\left(\text { lempung) } \gamma=\mathrm{yat}=1814 \mathrm{~kg} / \mathrm{cm}^{2}\right. \\
C u=0.20 \mathrm{~kg} / \mathrm{cm}^{2} \\
==0^{\circ}\end{array}$ \\
\hline
\end{tabular}

\section{Daya Dukung Berdasarkan Poulos and David;}

Tabel 13. Lapisan tanah dan jenis tanah

Untuk $\Phi^{0}=35^{0}$ Berdasarkan gambar $4.2 \mathrm{~b}$ maka diperoleh $\mathrm{Ks} \tan \Phi^{0}=0.5$, kemudian lihat gambar 4.1 maka $\mathrm{Nq}=75$. Lihat gambar $4.2 \mathrm{a}$ diperoleh $\mathrm{Zc} / \mathrm{d}=6.5$, maka $\mathrm{Zc}=3.25$ meter.

Untuk $\Phi^{0}=30^{0}$ Berdasarkan gambar 4.2b maka diperoleh $\mathrm{Ks} \tan \Phi^{0}=0.10$, kemudian gambar 4.1 maka $\mathrm{Nq}=32.5$, Lihat gambar 4.2a diperoleh $\mathrm{Zc} / \mathrm{d}=5.5$, maka $\mathrm{Zc}=2.75$ meter. Untuk ukuran tiang yang seragam maka $\mathrm{F} \omega=1$. Berdasarkan gambar 4.3 menurut Tomlinson untuk;
1. $\mathrm{Cu}=21 \mathrm{kN} / \mathrm{m}^{2}---\mathrm{Ca} / \mathrm{Cu}=1.25$, jadi $\mathrm{Ca}=26.25 \mathrm{kN} / \mathrm{m}^{2}$
2. $\mathrm{Cu}=18 \mathrm{kN} / \mathrm{m}^{2}---\mathrm{Ca} / \mathrm{Cu}=1.25$, jadi $\mathrm{Ca}=22.50 \mathrm{kN} / \mathrm{m}^{2}$
3. $\mathrm{Cu}=23 \mathrm{kN} / \mathrm{m}^{2}$---- $\mathrm{Ca} / \mathrm{Cu}=1.00$, jadi $\mathrm{Ca}=23.00 \mathrm{kN} / \mathrm{m}^{2}$
4. $\mathrm{Cu}=20 \mathrm{kN} / \mathrm{m}^{2}----\mathrm{Ca} / \mathrm{Cu}=1.25$, jadi $\mathrm{Ca}=25.00 \mathrm{kN} / \mathrm{m}^{2}$

Untuk Lapisan :

1. $\mathrm{Pu}=\int \mathrm{F} \omega . \mathrm{C} . \sigma^{\prime} \mathrm{v} \mathrm{Ks} \tan \Phi \mathrm{a} \mathrm{dz}+\mathrm{Ab} . \sigma^{\prime} \mathrm{v} \cdot \mathrm{Nq}-\mathrm{W}$

$\mathrm{Pu}=\int 1 \times 1.57 \times(17.36 \times 0.5) \times 1.36 \times \mathrm{dz}+0.2 \times 7.36 \times 0.5 \times 75-\mathrm{W}$

$\mathrm{Pu}=1 \times 1.57 \times(17.36 \times 0.5) \times 1.36 \times 0.5+0.2 \times 7.36 \times 0.5 \times 75-\mathrm{W}$

$\mathrm{Pu}=133.61-\mathrm{W}$

2. $\mathrm{Pu}=\int \mathrm{C} . \mathrm{Ca} . \mathrm{dz}+\mathrm{Ab}\left(\mathrm{Cu} . \mathrm{Nc}+. \sigma^{\prime} \mathrm{bv}\right)-\mathrm{W}$

$\mathrm{Pu}=\int 1.57 \times 26.25 \mathrm{xdz}+0.2\{21 \times 9+.(17.04-10) \times 3\}-\mathrm{W}$ 
$\mathrm{Pu}=1.57 \times 26.25 \times 2.5+0.2\{21 \times 9+.(17.04-10) \times 3\}-\mathrm{W}$

$\mathrm{Pu}=145.05-\mathrm{W}$

Hasil selanjutnya lihat table

Tabel 14. Persmaan friction dundung tiang pancang

\begin{tabular}{ll}
\hline Lapian tanah & Bentuk persamaan \\
\hline Lapisan 1 (Pasir) & $\mathrm{Pu}=133.61-\mathrm{W}$ \\
Lapisan 2 (Lempung) & $\mathrm{Pu}=145.05-\mathrm{W}$ \\
Lapisan 3 (Lempung) & $\mathrm{Pu}=387.05-\mathrm{W}$ \\
Lapisan 4 (Pasir) & $\mathrm{Pu}=835.36-\mathrm{W}$ \\
Lapisan 5 (Lempung) & $\mathrm{Pu}=158.94-\mathrm{W}$ \\
Lapisan 6 (Lempung) & $\mathrm{Pu}=77.75-\mathrm{W}$ \\
$\mathrm{W}=0.25 \times 3.14 \times 0.5 \times 0.5 \times 24 \times 16=$ & $\mathrm{Pu}$ total $=(33.61+145.05+387.05+835.36+158.94+$ \\
$75.36 \mathrm{Kn}$ & $77.75)-75.36=1662 \mathrm{kN}$ \\
Pijin $=\mathrm{Pu}$ total $/ 2=1662 / 2=831 \mathrm{kN}>538.30 \mathrm{kN}(\mathrm{OK} !)$
\end{tabular}

\section{KESIMPULAN}

Berdasarkan hasil penelitian dapat disimpulkan bahwa: Dimensi tiang bored pile tunggal dengan penampang bulat diameter $50 \mathrm{~cm}$ untuk meimkul beban dari struktur atas gedung sebesar $538.30 \mathrm{kN}$. Maka hasil analisis metode CPT memperoleh daya dukung sebesar 590,65 kN pertiang, metode SPT daya dukung sebesar 676,3 kN pertiang, Metode Paulos dan Davis untuk tiang tunggal daya dukung sebesar $831 \mathrm{kN}$ per tiang. Karena hasil analisis daya dukung berkisar dari $590.65-831.00 \mathrm{kN}>538.30 \mathrm{kN}$ maka daya dukung pondasi aman. Maka pondasi bored pile tiang tunggal juga layak untuk memikul beban layan yang diberikan sebesar $538.30 \mathrm{kN}$.

\section{DAFTAR PUSTAKA}

Anonimus. (1997), Rekayasa Fundasi II "Fundasi Dangkal dan Fundasi Dalam”. Jakarta : Gramedia. Bowles, J. E. (1977), Foundation Analysis and Design. $2^{\text {nd }}$ ed. New York : McGraw Hill

Bowles, J. E. (1984), Analisa dan Desain Pondasi Jilid 2. Terjemahan oleh Pantur Lilaban. Jakarta : Erlangga

Bowles, J. E. (1989), Sifat-sifat fisik dan geoteknis tanah dan mekanika tanah. Edisi kedua. Jakarta : Erlangga

Gow Tjie Liong. April (1997). Kendala Aplikasi Perencanaan Daya dukung tiang. Majalah Konstruksi (pp. 41-42) Jakarta.

Poulos, H.G. and Davis, E.H. (1980). Pile Foundation Analisys and Design. New York : McGraw Hill Sardjono, HS. (1991). Pondasi Tiang Pancang Jilid 1 dan Jilid 2. Sinar Wijaya. Surabaya.

Suyono Sastrodarsono dan Kazuto Nakazawa, (1984). Mekanika Tanah dan Teknik Pondasi. Cetakan ketiga. Jakarta : Pradnya Paramita.

Taylor, D.W.. (1972). Foundation of Soil Mechanics. Tokyo : Jhon Wiley and Sons.

Tomlison, MJ. (1997). Pile Design and Contruction Practice. The Garden City Press.

Wayne, C. Teng. (1981). Foundation Design. New Delhi. Practice Hall of India private Limited.

Wora, M. (1998). Studi Perbandingan Perencanaan Pondasi Tiang Pancang Beton dan Bored Pile pada Proyek Rumah Sakit Internasional Surabaya. Skripsi S-1. Universitas Widya Kartika Surabaya.

Wora, M. (2013). Studi Evaluasi Daya Dukung Pondasi Tiang Pancang Beton pada Proyek Pembangunan Gedung Rumah Sakit Internasional Surabaya. Jurnal Teknosiar, Vol. 2 Oktober 2013 p: $44-55$ 